Research Article

\title{
Assessment of Dietary Pattern of People Living in a Rural Area of Bihar
}

\author{
Mayank Rahul', Sonia Tiwari
}

${ }^{1}$ Assistant Professor, ${ }^{2}$ Associate Professor, Dept. of Community Medicine, SAMC \& PGI, Indore, Madhya Pradesh, India. DOI: https://doi.org/10.24321/2454.325X.202013

\section{I $\quad \mathbf{N} \quad \mathbf{F} \quad \mathbf{O}$}

\section{Corresponding Author:}

Mayank Rahul, Dept. of Community Medicine,

SAMC \& PGI, Indore, Madhya Pradesh, India.

E-mail Id:

mayank.rahul@gmail.com

Orcid Id:

https://orcid.org/0000-0002-2383-2657

How to cite this article:

Rahul M, Tiwari S. Assessment of Dietary Pattern of People Living in a Rural Area of Bihar. Int $J$ Preven Curat Comm Med 2020; 6(3): 17-20.

Date of Submission: 2020-06-15

Date of Acceptance: 2020-09-16

\section{$\begin{array}{llllllll}\mathbf{A} & \mathbf{B} & \mathbf{S} & \mathbf{T} & \mathbf{R} & \mathbf{A} & \mathbf{C} & \mathbf{T}\end{array}$}

Introduction: There is a trend of declining cereal intake particularly coarse cereals and really low increase of consumption of other food items within the rural diet, which has often been explained as an expected outcome of economic growth.

Aims \& Objectives: 1). To observe the dietary pattern of different food items and their timely consumption. 2). To assess the consumption and practices of daily food items used in kitchen.

Methodology: It was a cross-sectional study done in Nathnagar areas (Bihar) in the month of March, 2017 with the help of pre-tested semi structured questionnaire amongst the rural population. Total 154 subjects were interviewed in one-month period.

Result: maximum participants 51 (33.11\%) belong to 22-27 years of age group and majority of the population were literate. It was also found that 127 (82.46\%) of participants consume green vegetables daily and daily consumption of beverages such as tea and coffee were seen common to 152 (98.7\%) participants. lodized Salt intake consumption was seen in majority 151 (98\%). Washing practices of cereals, at least two times a day was seen in 94 (61\%) participant and it was also observed that 123 (79.87\%) participants practiced washing of vegetables before cutting.

Conclusion: Most of them where vegetarian by diet. As of education part all most all the participants were from the literate groups which depicts a good overview of society regarding studies. Many of them were aware of their consumption of food and its pattern, still few were lagging. Overall, everyone had different pattern of food habit and it shows that much work has to be done in the field of health dimension with the help of education and motivation and through implementation of healthy life style behaviour in terms of nutrition and its monitoring from time to time.

Keywords: Dietary Pattern, Cereal Intake, Nutrients 


\section{Introduction}

The dietary and nutrition transition has been characterized by the improved agricultural practices, food supplies and advances in food processing techniques, while making more food available to people has resulted in imbalanced nutrient intake resulting in changes the profile for health. ${ }^{1}$

There is a trend of declining cereal intake particularly coarse cereals and really low increase of consumption of other food items within the rural diet, which has often been explained as an expected outcome of economic growth. These changes in diet pattern, however, are not uniform rather vary across various socio-economic groups. ${ }^{2}$ Such differential access to food has resulted in widening inequalities among these groups in terms of nutrition intake, which in turn may lead to inequalities in health outcomes. While with increase in per capita income, decline in cereal consumption is expected to some extent, it is important to note that cereals are considered to be among the best source of energy and they also provide important nutrients to the body but they lack some micronutrients such as vitamins and minerals. ${ }^{3}$ This study was undertaken to observe the dietary pattern of different food items and their timely consumption and practices of daily food items used in kitchen.

\section{Methodology}

It was a cross-sectional study done in Nathnagar areas (Bihar) in the month of March, 2017 with the help of pretested semi structured questionnaire amongst the rural population. A house to house survey was performed in which the selection of participants was done by random sampling method. All people above 15 yrs. of age and those who were willing to participate in the study were included in the study.

Those who refused to participate in the study were excluded from the study. Total 154 subjects were interviewed in onemonth period. Prior verbal consent was taken from each subject in study before giving him or her the pretested semistructured questionnaire. The questionnaire consisted of questions related to their daily household consumption and practices. The collected data was entered in the excel sheet. The data analysis was done with the help of appropriate statistical test at the end of study.

\section{Result}

Table 1, describes age and sex wise distribution of the participants, where it was found that the maximum participants 51 (33.11\%) belong to 22-27 years of age group. Table 2, describes the educational status of the participants according to their gender. Majority of the population were literate. Table 3, describes the frequency of consumption of different food items. It was found 127
(82.46\%) of participants consumed green vegetables daily. Daily consumption of beverages such as tea and coffee were found common to 152 (98.7\%) participants. It was also found that 94 (61\%), 91 (59\%) and 92 (59.7\%) were found to consume dal, pickle and rice on daily basis respectively. Milk was never consumed by 24 (15.5\%) participants. Sprouts intake is must but in the study majority $114(74 \%)$ took it sometimes i.e. occasionally. Table 4, shows different uses of daily food items according to the population. lodized salt intake consumption was seen in majority 151 (98\%). Use of mustard oil and flour without choker in the kitchen was found to be 55 (35.7\%) and 113 (73.37\%) respectively. Washing practices of cereals, at least two times a day was seen in 94 (61\%) participants and it was also observed that $123(79.87 \%)$ participants practiced washing of vegetables before cutting. Table 5, shows the moderate pattern of consumption of vegetarian foods by 65 (42.2\%) participants while 49 (31.8\%) were eggiterian.

\section{Table I.Age and gender-wise distribution of participants}

\begin{tabular}{|c|c|c|c|c|}
\hline S. No. & Age-Group & Males & Females & Total (\%) \\
\hline 1. & $16-21$ & 10 & 11 & $21(13.63)$ \\
\hline 2. & $22-27$ & 25 & 26 & $51(33.11)$ \\
\hline 3. & $28-33$ & 26 & 10 & $36(23.37)$ \\
\hline 4. & $34-39$ & 19 & 12 & $31(20.12)$ \\
\hline 5. & $40-45$ & 7 & 3 & $10(6.49)$ \\
\hline 6. & $46-50$ & 2 & 3 & $5(3.24)$ \\
\hline & Total & 89 & 65 & 154 \\
\hline
\end{tabular}

Table 2.Gender wise distribution of educational status

\begin{tabular}{|c|c|c|c|c|}
\hline S. No. & $\begin{array}{c}\text { Educational } \\
\text { status }\end{array}$ & Males & Females & Total (\%) \\
\hline 1. & Illiterate & 0 & 3 & $3(1.94)$ \\
\hline 2. & Primary & 2 & 2 & $4(2.59)$ \\
\hline 3. & Secondary & 18 & 30 & $48(31.16)$ \\
\hline 4. & H. Secondary & 47 & 12 & $59(38.31)$ \\
\hline 5. & Graduate & 22 & 18 & $40(25.97)$ \\
\hline & Total & 89 & 65 & 154 \\
\hline
\end{tabular}

\section{Discussion}

In a study done by Prakruthi and Prakash in the state of Karnataka, it was found that there was nutritional transition among rural Indian women; a majority (45.7\%) were between the age group of 25-30 years, while the others were observed between $31-35$ and $36-40$ years. They found a high consumption of fats from $146.5 \%$ to $212 \%$ of the recommended intake. ${ }^{1}$ The present study shows that It was found that $55 \%$ of the participants used oils daily in food. 
Table 3.Timely Consumption of different food items

\begin{tabular}{|c|c|c|c|c|c|c|}
\hline Food Items & $\begin{array}{c}\text { Eat daily } \\
\text { (\%) }\end{array}$ & $\begin{array}{c}\mathbf{1 - 2} \text { times a } \\
\text { week (\%) }\end{array}$ & $\begin{array}{c}\mathbf{3 - 4} \text { times a } \\
\text { week (\%) }\end{array}$ & $\begin{array}{c}\mathbf{1 - 2} \text { times a } \\
\text { month (\%) }\end{array}$ & $\begin{array}{c}\text { Sometimes } \\
\text { (\%) }\end{array}$ & Never (\%) \\
\hline Chapattis & 154 & 00 & 00 & 00 & 00 & 00 \\
\hline Dal & $94(61.03)$ & $43(27.9)$ & $14(9.09)$ & $3(1.94)$ & 00 & 00 \\
\hline Rice & $91(59.09)$ & $39(25.3)$ & - & $8(5.19)$ & $16(10.3)$ & 00 \\
\hline Milk & $79(51.21)$ & $6(3.8)$ & $7(4.54)$ & $3(1.94)$ & $35(22.7)$ & $24(15.5 \%)$ \\
\hline Ghee/ Dalda & $33(21.42)$ & $19(12.3)$ & $1(0.64)$ & $61(39.61)$ & $40(25.9)$ & 00 \\
\hline Green vegetables & $127(82.4)$ & $1(0.64)$ & $1(0.64)$ & $2(1.29)$ & $23(14.9)$ & 00 \\
\hline Kand & $10(6.4)$ & $14(9.09)$ & $14(9.09)$ & $58(37.6)$ & $58(37.6)$ & 00 \\
\hline Sprouts & $13(8.4)$ & $12(7.7)$ & 00 & $12(7.79)$ & $114(74)$ & $3(1.94)$ \\
\hline Tea/ coffee & $152(98.7)$ & 00 & 00 & 00 & $2(1.29)$ & 00 \\
\hline Soft drinks & $34(22.07)$ & $2(1.29)$ & $4(2.59)$ & $18(11.68)$ & $79(51.21)$ & $17(11.03)$ \\
\hline Pickle & $92(59.7)$ & $8(5.19)$ & $3(1.94)$ & $1(0.64)$ & $45(29.2)$ & $5(3.2)$ \\
\hline Salad & $72(46.7)$ & $8(5.19)$ & $14(9.09)$ & $1(0.64)$ & $55(35.7)$ & $4(2.5)$ \\
\hline
\end{tabular}

Table 4.Use of daily food items and common practices in kitchen

\begin{tabular}{|c|c|c|}
\hline S. No. & Food items & Total popul. (\%) \\
\hline \multirow{2}{*}{ Use of Salts } & lodized salt & $151(98.5)$ \\
\hline & Non- lodized salt & $3(1.94)$ \\
\hline \multirow{4}{*}{ Use of oils } & Mustard oil & $55(35.7)$ \\
\hline & Groundnut oil & $43(27.9)$ \\
\hline & Soya bean oil & $48(31.16)$ \\
\hline & Mixed oil & $8(5.19)$ \\
\hline \multirow{2}{*}{ Flour used } & With choker & $41(26.62)$ \\
\hline & Without choker & $113(73.37)$ \\
\hline \multirow{4}{*}{$\begin{array}{l}\text { No. of times washing of cereals (dal \& } \\
\text { rice) }\end{array}$} & Don't wash & 0 \\
\hline & 1 time & $45(29.22)$ \\
\hline & 2 times & $94(61.03)$ \\
\hline & 3 times & $15(9.7)$ \\
\hline \multirow{3}{*}{ When do you wash vegetables } & After cutting & $29(18.83)$ \\
\hline & Before cutting & $123(79.87)$ \\
\hline & Both & $2(1.29)$ \\
\hline
\end{tabular}

Table 5.Describing the types of food consumption

\begin{tabular}{|c|c|c|c|}
\hline Types of food & Males & Females & Total (\%) \\
\hline Veg. & 37 & 28 & $65(42.2)$ \\
\hline Non - Veg. & 19 & 7 & $26(16.8)$ \\
\hline Eggiterian & 33 & 16 & $49(31.8)$ \\
\hline Occasionally Non - Veg. & 0 & 14 & $14(9)$ \\
\hline
\end{tabular}

The fat consumption was much higher than recommendation in all the age groups ranging from 146.5 to $212 \%$ of the desired intake with marginally significant difference between groups.
A study found, among women within the low mixed diet cluster, quite three-fifth consume milk/ curd, pulses/ beans and other vegetables on a day to day whereas only negligible proportions seem to possess consumed eggs, 
meat/ chicken/ fish. This clearly points precisely to the distinctiveness of the low mixed diet cluster. About $99 \%$ of girls during this cluster consume important vegetarian foods; quite $60 \%$ of them tend to consume vegetarian foods on a day to day. 3 Similarly, the present study found $55 \%$ of participants consumed vegetarian food items daily.

A study found that majority of women in India (85\%) consumed pulses or beans and green leafy vegetables at least once a week with the exception of Kerala. Consumption of egg and meat products was found relatively low in several states, particularly in the North. ${ }^{4}$

George et al in a study in Kerala found penurious diet patterns among females. They found $64.6 \%$ were used to skip one meal in a day and $86.7 \%$ consumed junk food with decreased consumption of Green leafy vegetables and no fruits. Contrary to this, the present study found daily consumption of green vegetables by $82.46 \%$ participants. ${ }^{5}$ According to the 1998 FAO report, the average Indian dietary intake is mostly deficient in the consumption of green leafy vegetables, milk and milk products and meat. ${ }^{6}$

\section{Conclusion}

Out of total population majority of the respondents belonged to the age group of 22-27 yrs. of age thereby the response what we got in the study showed a peak view of young age choices. While most of them where vegetarian by diet. As of education part all most all the participants were from the literate groups which depicts a good overview of society regarding studies. Many of them were aware of their consumption of food and its pattern, still few were lagging. Chapatti was the most common food item which was included at least once in a day. Next in the row comes rice, dal and milk which were consumed daily by the respondents. Consumption of green vegetables was seen daily in their diets on majority basis, but on the personal contrary the amount consumed was not as per RDA. Pickles and salad were common and consumed daily. Use of iodized salt was seen to be practiced by majority of them. More than fifty percent of the participants did proper practice of washing cereals and vegetables. Overall, everyone had different pattern of food habit and it shows that much work has to be done in the field of health dimension with the help of education and motivation and through implementation of healthy life style behaviour in terms of nutrition and its monitoring from time to time.

\section{Financial Support: None}

\section{Conflict of Interest: None}

\section{References}

1. Prakruthi BS, Prakash, Jamuna. Nutritional status and dietary pattern of Indian rural women with reference to energy intake and expenditure. Journal of Community nutrition and Health 2013; 44-51.

2. Gupta A, Mishra D. Food Consumption Pattern in Rural India: A Regional Perspective. Journal of Economic and Social Development 2014; 10: 1-16.

3. Gopalan C. Dietary Guidelines for Indians - A Manual. New Delhi: GOI; 2016.

4. Padmadas SS, Dias JG, Willekens F. Understanding Dietary Intake Behavior of Women in India: A Latent Class Approach. From: https://www.researchgate. net/publication/254096589_Understanding_Dietary_ Intake_Behavior_of_Women_in_India_A_Latent_ Class_Approach. Accessed 15/06/2020.

5. George L, Sabitha N, Rehman R. Dietary Behaviours among Adolescent Girls in Pathanamthitta District, Kerala. Int J Preven Curat Comm Med 2020; 6(3): 3-9.

6. Food and Agricultural Organization. FAO-Nutrition country profile of India, Food and Agricultural Organization of the United Nations: Rome. 1998. 